\title{
TREADMILL PROTOCOLS FOR DETERMINATION OF MAXIMUM OXYGEN UPTAKE IN RUNNERS
}

\author{
T. R. McCONNELL and B. A. CLARK*
}

Cardiac Rehabilitation Unit and Exercise Laboratory, Saint Francis Hospital and *Medical Center, Hartford, Connecticut, USA

\section{ABSTRACT}

Four testing protocols were completed by each of 10 runners using a common speed for protocols 1 and 2 (P1 and P2), each runner's training pace for protocol 3 (P3) and a speed selected manually by the runner for protocol 4 (P4). Stages were increased by $2.5 \%$ grade every 2 min for each protocol except for P1, which had 1 min stages. There were no significant differences in maximum oxygen uptake $\left(\mathrm{VO}_{2} \mathrm{max}\right)$ between protocols $\left(\mathrm{P} 1,65.0 \pm 5.6 \mathrm{ml}^{\mathrm{k}} \mathrm{kg}^{-1} \mathrm{~min}^{-1} ; \mathrm{P2}, 64.5 \pm 5.3 \mathrm{ml} . \mathrm{kg}^{-1} \mathrm{~min}-1\right.$;

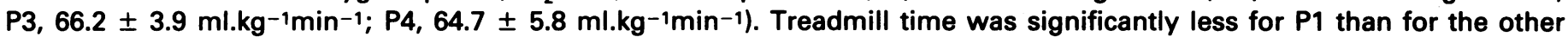
protocols. The rate of perceived exertion obtained at maximal exercise during P1 was less than that obtained during the other three protocols. Heart rate was significantly lower $(P<0.05)$ at any level of submaximal $\mathrm{VO}_{2}$ during $P 3$ than during the other protocols. We recommend a testing protocol using speeds approximating the runner's training pace and 1 min stages. This may result in lower perception of difficulty and HR throughout the test and shorter testing times.

Key words: Maximal oxygen uptake, Treadmill running protocols

\section{INTRODUCTION}

The most commonly selected protocols for assessing maximal oxygen consumption $\left(\mathrm{VO}_{2}\right.$ max $)$ in trained runners have used the same speed for all runners or different speeds and stage increments according to the subjects' predicted $\mathrm{VO}_{2} \max$ (Åstrand and Rodahl, 1977; Costill and Fox, 1969). The most desirable testing protocol may be one that is similar to the runner's training environment (Davies et al, 1984). This may be most closely duplicated during a test by allowing the runners to run at their usual training pace or allowing them to select the running speed used during the test.

This study investigated trained runners who performed four $\mathrm{VO}_{2}$ max tests each. During two of the tests, the same treadmill speed was used for all runners. During the other two tests the subjects ran at their usual training pace for one and a self-selected testing speed was used for the other. Differences in maximal and submaximal physiological responses were evaluated. In addition, because it is desirable that testing time should be short, differences between tests using 1 versus $2 \mathrm{~min}$ stages were investigated.

\section{MATERIALS AND METHODS}

Ten well trained male runners (age $=33.6 \pm 8.6 \mathrm{yrs}$ ) performed four $\mathrm{VO}_{2}$ max tests each (Table I). Their distance run in training ranged from 40.3 to $104.8 \mathrm{~km}$ per week at a mean pace of $3.87 \mathrm{~m} . \mathrm{s}^{-1}$. Medical clearance and appropriate informed consent was obtained for all runners.

TABLE I

Subjects' descriptive data

\begin{tabular}{lcccc}
\hline Subject & $\begin{array}{c}\text { Age } \\
(\mathrm{yrs})\end{array}$ & $\begin{array}{c}\text { Wt } \\
(\mathrm{kg})\end{array}$ & $\begin{array}{c}\text { Training mileage } \\
\left(\mathrm{km}^{2} \text {.week-1) }\right.\end{array}$ & $\begin{array}{c}\text { Training Pace } \\
\left({\left.\mathrm{m} . \mathrm{s}^{-1}\right)}^{-1}\right.\end{array}$ \\
\hline Mean & 33.6 & 65.2 & 57.7 & 3.87 \\
SD & 8.6 & 6.6 & 20.2 & 0.23 \\
Range & $20-50$ & $54.4-76.5$ & $40-105$ & $3.46-4.20$ \\
\hline
\end{tabular}

Address for correspondence:

Timothy R. McConnell, PhD, FACSM

Director, Cardiac Rehabilitation

Department of Cardiology

Geisinger Medical Center

Danville, PA 17822

USA
Four treadmill testing protocols were randomly ordered for each runner. The tests were scheduled at least 48 hours apart and at the same time each day. The runners were instructed not to eat a large meal for at least 3 hours before a test and to avoid strenuous workouts for the 24 hours preceding the test. All tests were performed on a motorised treadmill.

Protocols 1 and 2 (P1 and P2) used the same speed (3.58 m.s $\left.{ }^{-1}\right)$, but different stage durations $(P 1=1 \mathrm{~min}$; P2 $=2 \mathrm{~min}$ ). This speed was selected based on reported training paces of runners questioned and protocols used for runners in previous investigations. The speed for P3 was the mean reported training pace for each runner $(3.89 \pm$ 0.22 m.s ${ }^{-1}$ ). During P4, speed was controlled manually by the runner during the warm-up period using toggle switches that were mounted on the front handrail support of the treadmill. The runners were instructed to select a speed that felt comfortable and would allow an "all out" maximal effort. The final warm-up speed was recorded and used for the remainder of the test. The runners were given no feedback as to the speed they selected. The mean selected speed was $3.53 \pm 0.50 \mathrm{~m} . \mathrm{s}^{-1}$.

The tests began with a $5 \mathrm{~min}$ warm-up at $0 \%$ grade during which the speed was increased gradually to the protocol's respective running speed. The runners were motivated verbally to continue as long as possible during all tests until they could no longer continue and grasped the front handrail support.

The runners breathed through a Hans-Rudolph two-way, non-rebreating valve (dead space $=115 \mathrm{ml}$ ) held in place by headgear apparatus. Expired air volumes were measured and presented as minute values using a Rayfield Air Meter (RAM-9200 Spirometer) with potentiometer output to an Apple II+ computer. Oxygen and carbon dioxide concentrations were determined by calibrated Beckman OM-11 and LB-2 gas analysers. Oxygen uptake, carbon dioxide production $\left(\mathrm{VCO}_{2}\right)$, and the respiratory exchange ratio (R) were computed and updated each min and at peak exercise. Heart rate was recorded by standard ECG procedures at the end of the rest and warm-up periods, during the last $15 \mathrm{~s}$ of each min of the test, and at peak exercise. Preceding the rest period, a $4 \mathrm{~cm}$ (1.25 in), 20 gauge intravenous teflon catheter was inserted in an antecubital vein. Samples were obtained during the last $30 \mathrm{~s}$ of the rest and warm-up periods, each workstage during P2, P3, and P4 and every other workstage during P1. Samples 
were also drawn immediately, 5 and $10 \mathrm{~min}$ post exercise (Gass et al, 1981; Lai and Lien, 1983). Whole blood determinations of lactic acid were performed immediately following each test using a Yellow Springs Instruments Model 23L Lactate Analyser. Whole blood lactic acid concentrations were adjusted according to the haematocrit to obtain plasma lactic acid concentrations. The highest value obtained was used as the maximum lactic acid concentration. Rate of perceived exertion was recorded during the last $30 \mathrm{~s}$ of warm-up, at the end of each workstage, and at peak exercise according to the methods originally described by Borg (1970).

One-way analysis of variance (ANOVA) with repeated measures was computed to determine if significant differences $(P<0.05)$ occurred between protocols for maximal values of oxygen consumption, blood lactic acid concentration, heart rate, respiratory exchange ratio, treadmill time and RPE max. Linear regression equations were computed for the heart rate and RPE responses to increasing $\mathrm{VO}_{2}$ for each protocol. The regression equations were compared statistically to determine possible differences with regards to slope, intercepot and residual variance (Snedecor and Cochran, 1967).

\section{RESULTS}

There were no significant differences between the four protocols for maximal values of $\mathrm{VO}_{2}$, heart rate, respiratory exchange ratio and blood lactic acid concentration (Table II). The maximum rate of perceived exertion was significantly less $(P<0.05)$ during $P 1(18.3 \pm 1.1)$ than during $P 3$ $(19.3 \pm 0.7)$. As expected, treadmill time was significantly less during P1 (10.1 min) than during P3 (11.8 min), P2 (13.1 $\mathrm{min})$, or P4 (13.6 $\mathrm{min})$. Also, treadmill time was significantly shorter for $P 3$ than $P 4(P<0.05)$. The regression line of heart rate versus $\mathrm{VO}_{2}$ had a significantly lower elevation (y-intercept) for P3 (76.78) than for P1 (86.15), P2 (81.53), or P4 (83.67). This resulted in a lower HR at every level of submaximal $\mathrm{VO}_{2}$ for $\mathrm{P} 3$ than during the other protocols (Fig. 1). There were no significant differences between slopes of the regression lines or in residual variances. Even though there was a trend for a lower RPE at every level of $\mathrm{VO}_{2}$ during P3 (Fig. 2), the differences between the slopes and elevation of the regression of $\mathrm{RPENO} \mathrm{N}_{2}$ did not obtain significance between protocols. There was an average increase in $\mathrm{VO}_{2}$ of

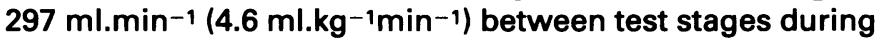
$P 2$. During $P 1$, the mean increase in $\mathrm{VO}_{2}$ between test stages was $271 \mathrm{ml} \cdot \mathrm{min}^{-1}\left(4.2 \mathrm{ml} . \mathrm{kg}^{-1} \mathrm{~min}^{-1}\right)$. When the rate of increase (slope) of $\mathrm{VO}_{2}$ with increasing intensity was compared between the regression of P1 (4.37) and P2 (4.69), the difference was not statistically significant.

\section{DISCUSSION}

We compared four testing protocols for measuring $\mathrm{VO}_{2}$ max in trained runners. Based on the recommendations of others (Gibson et al, 1979; Harrison et al, 1980; Pollock, 1977; Taylor et al, 1955), 3.58 m.s $\mathrm{s}^{-1}$ was used as a common speed for all runners (P1 and P2). During P3 each runner ran at their reported training pace $\left(3.89 \pm 0.22 \mathrm{m.s}^{-1}\right)$ while P4 allowed the runners to select their running pace manually

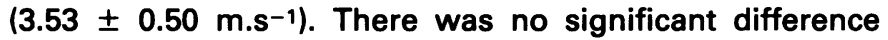
between the four protocols for $\mathrm{VO}_{2} \max$ (Table II). This agrees with the findings of Stamford (1975) who found that the $\mathrm{VO}_{2}$ max values were similar for speeds ranging from 2.47 to $4.47 \mathrm{~m} . \mathrm{s}^{-1}$ in a high fitness group. Stamford concluded that higher running speeds may be most appro-

\section{TABLE ॥}

Maximal values for maximum oxygen uptake $\left(\mathrm{VO}_{2}\right.$ max), heart rate (HR max), respiratory exchange ratio (R max), blood lactic acid concentration (LA max), treadmill running time ( $T$ T max) and rating of perceived exertion (RPE max) for four different protocols. Mean \pm SD

\begin{tabular}{lcccc}
\hline & P1 & P2 & P3 & P4 \\
\hline VO $_{2} \max$ & $65.0 \pm(5.6)$ & $64.5 \pm(5.3)$ & $66.2 \pm(3.9)$ & $64.7 \pm(5.8)$ \\
HR max & $183.6 \pm(9.2)$ & $185.3 \pm(9.1)$ & $184.6 \pm(8.1)$ & $184.2 \pm(8.7)$ \\
$R$ max & $1.25 \pm(0.10)$ & $1.15 \pm(0.10)$ & $1.16 \pm(0.07)$ & $1.19 \pm(0.14)$ \\
LA max & $10.9 \pm(2.0)$ & $10.0 \pm(2.0)$ & $10.5 \pm(1.9)$ & $11.20 \pm(1.7)$ \\
TT & $10.1 \pm(0.6)+\S \neq$ & $13.1 \pm(1.2)$ & $11.8 \pm(1.1) \neq$ & $13.6 \pm(2.5)$ \\
$R P E \max$ & $18.3 \pm(1.1)$ & $18.9 \pm(0.9)$ & $19.3 \pm(0.7)^{*}$ & $19.2 \pm(0.6)$ \\
\hline
\end{tabular}

$\mathrm{VO}_{2} \max \quad\left(\mathrm{ml} \mathrm{kg}^{-1} \mathrm{~min}^{-1}\right) \quad$ * (sig. diff. from $\left.\mathrm{P} 1, \mathrm{p}<0.05\right)$

$H R$ max (beats. $\min ^{-1}$ ) $\quad+$ (sig. diff. from $P 2, p<0.01$ )

LA max (mmol. $\left.\mathrm{I}^{-1}\right) \quad$ \$ (sig. diff. from $\mathrm{P3}, \mathrm{p}<0.05$ )

$\pi \quad(\min ) \quad \neq($ sig. diff. from $P 4, p<0.01)$

priate when testing extremely well trained individuals.

Morgan (1985) reported that exercise metabolism and efficiency of movement is dependent in part on cognition (thought), perception (sensations), and affect (feelings); therefore, perceived exertion or effort sense are associated with changes in the physiological response to exercise. The runners may have been more familiar and comfortable with running at their training pace. This may help to explain why heart rate was less and RPE had a tendency to be lower at every level of $\mathrm{VO}_{2}$ during $\mathrm{P} 3$ than during the other protocols (Figs. 1 and 2).

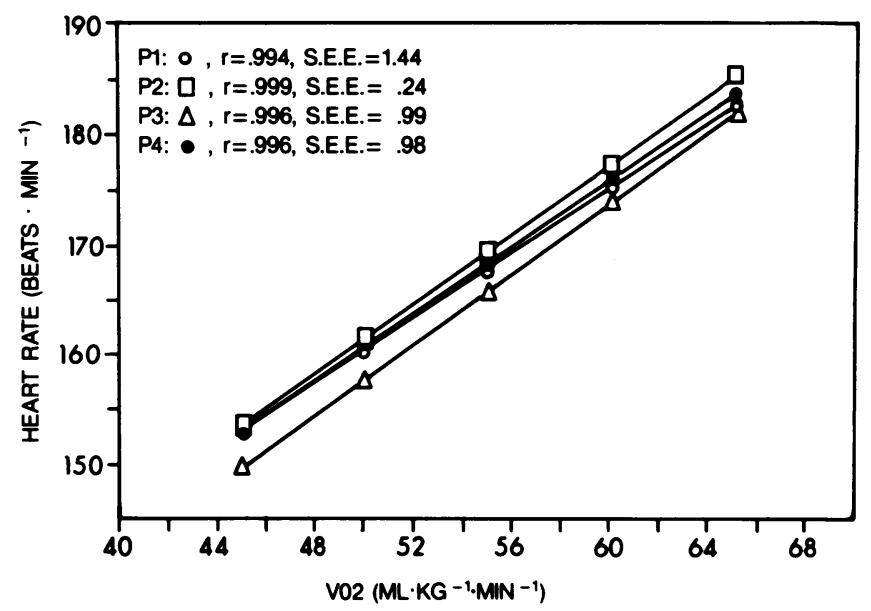

Fig. 1

Allowing the subjects to select their own running speed during P4 was not effective. Even though the mean selected speed ( $\left.3.53 \mathrm{~m} . \mathrm{s}^{-1}\right)$ approximated the speeds used for $P 1$ and $P 2$, a wide range of speeds was selected (2.63 to $\left.4.39 \mathrm{~m} . \mathrm{s}^{-1}\right)$. Using self-selected speeds did not result in any physiological responses that differed from those obtained when the same speed was used for all runners (P2) and treadmill time was longer.

The stage increments of $2.5 \%$ grade showed an average

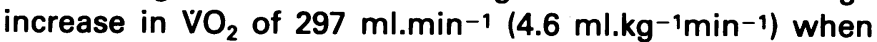
2 min stages were used for $P 2$. These results are similar to those of Taylor et al (1980) who reported increases in $\mathrm{VO}_{2}$ of

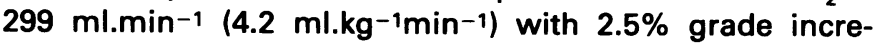
ments at a constant speed. When 1 min stages were used during $\mathrm{P} 1, \mathrm{VO}_{2}$ increased by $271 \mathrm{ml} \cdot \mathrm{min}^{-1}\left(4.2 \mathrm{ml} . \mathrm{kg}^{-1} \mathrm{~min}^{-1}\right)$. The slope of the regression equations for the increase in 


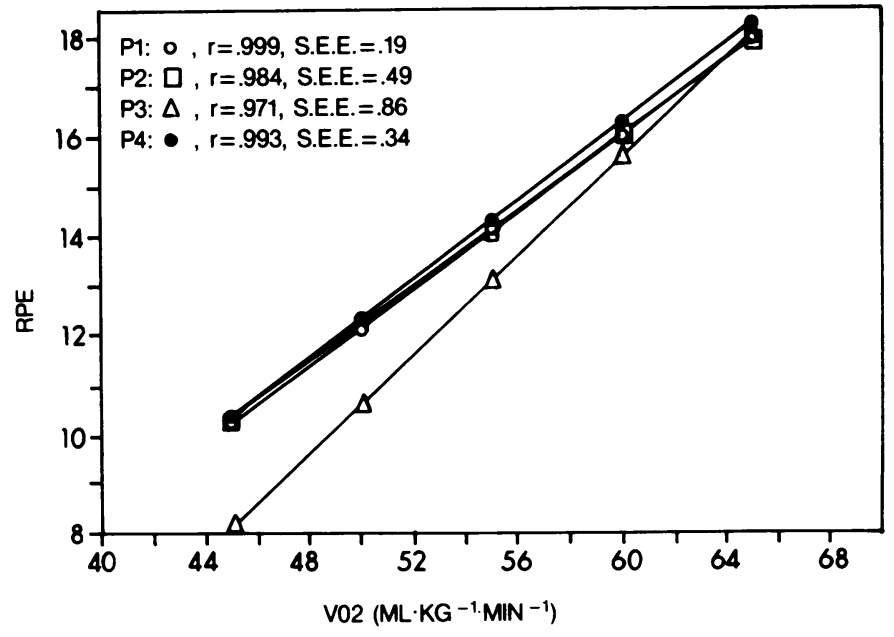

Fig. 2

$\mathrm{VO}_{2}$ with an increase in grade was not significantly different between P1 (4.37) and P2 (4.69). This indicates that $1 \mathrm{~min}$ stages appear to allow an adequate $\mathrm{VO}_{2}$ kinetic response. Treadmill time was significantly less during P1 (10.1 min) than during the other protocols (Table II) and was consistent with the recommendations that a total testing time of 7 to $10 \mathrm{~min}$ in length is adequate to allow appropriate maximal physiological adjustments (Pollock et al, 1976).

There were no differences between protocols in terms of the maximal physiological data obtained, with the exception of RPE max. RPE max was lowest during P1, and significantly lower during $P 1$ than during $P 3(P<0.05)$. Therefore, it appears that $1 \mathrm{~min}$ stages are adequate for a $\mathrm{VO}_{2}$ max test and the shorter testing time may have resulted in a lower perception of test difficulty at peak exercise with no reduction in $\mathrm{VO}_{2}$ max when compared to protocols of a longer duration.

\section{CONCLUSIONS}

Even though all of the protocols tested elicited similar $\mathrm{VO}_{2}$ max data ( $1.1 \%$ variance between means), we suggest a protocol using $1 \mathrm{~min}$ test stages and running speeds that approximate the runner's training pace for the assessment of $\mathrm{VO}_{2}$ max. This may result in a lower perception of difficulty throughout the test due to enhanced subject comfort and shorter testing times.

\section{ACKNOWLEDGEMENTS}

The authors would like to thank Drs. Steven F. Siconolfi and David D. Swett, Jr. for their critical review of the manuscript. Grant support was received from the Saint Francis Hospital Association, Hartford, CT.

\section{References}

Astrand, P. O., Rodahl, K., 1977 "Textbook of work physiology: physiological basis of exercise", 2nd ed., McGraw Hill Company, New York, p. 297, 341-342.

Borg, G., 1970 "Perceived exertion as an indicator of somatic stress". Scand.J.Rehab.Med. 2: 92-98.

Costill, D. L., Fox, E. L., 1969 "Energetics of marathon running". Med.Sci.Sports 1: 81-86.

Davies, B., Daggett, A., Jakeman, P., Mulhall, J., 1984 "Maximal oxygen uptake utilising different treadmill protocols". Brit.J.Sports Med. 18: 74-79.

Gass, G. C., Rogers, S., Mitchell, R., 1981 "Blood lactate concentration following maximal exercise in trained subjects". Brit.J.Sports Med. 15: 172-176.

Gibson, T. M., Harrison, M. H., Wellicome, R. M., 1979 "An evaluation of a treadmill work test". Brit.J.Sports Med. 3: 6-11.

Harrison, M. H., Brown, G. A., Cochran, L. A., 1980 "Maximal oxygen uptake: Its measurement, application, and limitations". Aviat.Space Environ.Med. 51: 1123-1127.

Lai, J. S., Lien, N. I., 1983 "Maximal blood lactate concentration and its recovery course after exhaustive graded treadmill exercise in young men". In: Biochemistry of exercise. (Ed.: H. G. Knuttgen, J. A. Vogel) Kinetics Publishers, Inc., pp. 411-414.

Morgan, W. P., 1985 "Psychogenic factors and exercise metabolism". Med.Sci.Sports Exerc. 17: 309-316.

Pollock, M. L., 1977 "Submaximal and maximal working capacity of elite distance runners. Part I: Cardiorespiratory aspects". Ann.N.Y.Acad.Sci. 301: 310-321.

Pollock, M. L., Bohannon, R. L., Cooper, K. H., Ayers, J. J., Ward, A., White, S. R. and Linnerud, A. C., 1976 "A comparative analysis of four protocols for maximal treadmill stress testing". Am. Heart J. 92: 39-46.

Snedecor, G. W. and Cochran, W. G., 1967 "Statistical methods", 6̣th ed., The lowa State University Press, Ames, pp. 432-436.

Stamford, B. A., 1975 "Maximal oxygen uptake during treadmill walking and running at various speeds". J.Appl.Physiol. 39: 386-389.

Taylor, H. L., Buskirk, E. and Henschel, A., 1955 "Maximal oxygen intake as an objective measure of cardiorespiratory performance". J.Appl.Physiol. 8: 73-80.

Taylor, H. L. and Rowell, L. B., 1980 "Exercise and metabolism. In: Structural and physiological aspects of exercise and sport". (Eds.: W. R. Johnson and E. R. Buskirk). Princeton Book Company, pp. 84-111.

Title:

Authors:

Publisher:

\section{REHABILITATION OF ATHLETIC INJURIES - AN ATLAS OF THERAPEUTIC EXERCISE}

Joseph S. Torg, Joseph J. Vegso and Elisabeth Torg

Wolfe Medical Publications, London 1987

Price: $£ 21.50 \quad 275$ pages Index. Numerous half-tone photographs

ISBN $081518820 X$

This book deals with range of motion, flexibility and strength whilst maintenance of cardio-respiratory fitness and specific sports skills are mainly ignored. The book is written for the professional in a well-appointed department of rehabilitation, many pages are devoted to strapping and fitting various types of brace (fifteen pages to knee braces) and indeed external joint splinting is not well-utilised in this country. Of necessity a number of exercises are repeated for differing injuries leading either to repetition or cross-referencing through the book; the cross-referencing is somewhat cumbersome. The book is fullyillustrated with photographs and bibliography at the end of each section which is separated into anatomical and injury-related divisions. The chapter on drug therapy displays a knowledge of the $10 \mathrm{C}$ banned list but is not an experienced guide for working within those restrictions as it mainly deals with the pharmacology of the banned drugs. The book also includes the regular use of Phenylbutazone which is banned in this country for sports injuries. No home exercises are given but all in all a useful attempt to rationalise rehabilitation exercises for soft tissues in a well-equipped gym or physiotherapy department, as long as the sportsman can attend regularly. 